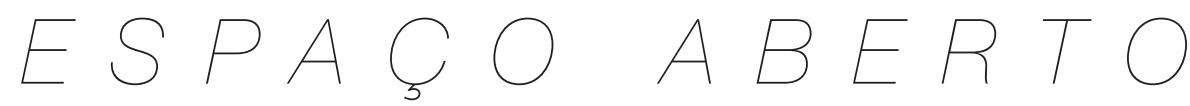

\title{
PROMOČÃO DO ENVELHECIMENTO \\ SAUDÁVEL: ADOCÃO DE UMA PRÁTICA MULTIDISCIPLINAR NA ATENÇÃO À SAÚDE DO IDOSO (UNISC)
}

Francisca Maria Assmann Wichmann ${ }^{1}$

Silvia Virginia Coutinho Areosa ${ }^{2}$

Nestor Pedro Roos ${ }^{3}$

resumo

Este artigo tem o propósito de socializar a experiência de um projeto de Extensão da Universidade de Santa Cruz do Sul (UNISC), Promoção do Envelhecimento Saudável ${ }^{4}$-, que abrange Enfermagem, Nutrição e Psicologia. É desenvolvido desde 1997 e vem se adequando às realidades, tendo por referência a experiência dos docentes nas ações para o envelhecimento com qualidade de vida, realizado há dez anos pela equipe interdisciplinar do Serviço Escola

Nutricionista, Doutora em Desenvolvimento Regional, Docente da UNISC.

Psicóloga, Doutora em Serviço Social, Docente da UNISC.

Enfermeiro, Mestre em Desenvolvimento Regional, Docente da UNISC.

4 Fazem parte deste projeto os acadêmicos Aline Bianca da Silva, Ana Paula de Lima, Claudemara Martins, Denise Maria Junqueira, Géli Bringmann e Patrícia Jost 
da UNISC. O objetivo é socializar a experiência, que reúne idosos ao longo do ano para a discussão de temas relacionados à saúde no envelhecimento. Cada área, por meio dos seus conhecimentos específicos, busca através de encontros de saúde e de atendimentos individualizados construir coletivamente o melhor processo de cuidado. Com as interlocuções ocorrem momentos ricos de trocas de experiências, conhecimentos, informações e intervenções para que o usuário seja percebido na sua integralidade e busque a responsabilidade frente a sua saúde. Os resultados demonstram uma melhora no nível de saúde, diminuindo complicações decorrentes das doenças crônicas.

palavras - chave:

Envelhecimento. Multiprofissionalidade. Grupos Operativos.

\section{Introdução}

O envelhecimento é um processo multidimensional, ou seja, depende de todas as vivências anteriores do indivíduo, desde sua infância até a maturidade, tanto sob o ponto de vista biológico quanto sócio - emocional e econômico. Essas vivências irão influir na capacidade de enfrentamento das modificações que ocorrem com o aumento da idade, traduzindo-se em diferentes modelos de velhice (RODRIGUES, 2000).

No Brasil e, em diversos outros países em desenvolvimento, o aumento da população idosa vem ocorrendo de forma muito rápida, sem a correspondente modificação nas condições de vida. Problemas de saúde, como as doenças crônicas não transmissíveis, cuja incidência aumenta, vêm ocupando lugar de destaque no perfil de mortalidade desses países. Este envelhecimento populacional determina um aumento nos recursos dos serviços de saúde do país, como nos seus custos, visto que, em geral, as doenças que acometem essa camada da população necessitam de tratamento por períodos prolongados e intervenção multidisciplinar para a prevenção do agravamento das sequelas já instaladas (ASSIS, 2004).

Considerando que o cenário nacional aponta para um número cada vez maior de idosos na população, e que estes idosos podem apresentar múltiplas doenças crônicas, sendo que estas doenças podem causar dependência, este século será marcado por novas necessidades de cuidado. Envelhecer significa prolongar a vida, vencer a morte precoce, e seguir existindo, realizando, 
criando vida. Este enfoque tem sido perseguido através da formação de Grupos Operativos para o Envelhecimento com Qualidade de Vida desde 1997, alojando-se no Serviço Escola da UNISC, que dispõe de atendimentos nas áreas de Enfermagem, Nutrição e Psicologia, com espaço apropriado para o atendimento individual e grupal dos pacientes deste projeto.

Trabalhar interdisciplinarmente, sobretudo quando se trata do campo da saúde que traz uma vertente teórica tradicionalmente curativa superar esta visão fragmentada para um entendimento global do indivíduo, enfatizando a promoção da saúde, representa um grande risco e um grande desafio, pois implica em enveredar por caminhos novos. É necessário ter ousadia e persistência para o avanço do conhecimento, lembrando que nenhum dos autores tem pleno domínio e conhecimento.

A atenção em grupos pode contribuir na promoção, proteção e controle dessas situações. Os grupos facilitam o exercício da autodeterminação e da independência, pois podem funcionar como rede de apoio que mobiliza as pessoas na busca de autonomia e sentido para a vida, na autoestima e, até mesmo, na melhora do senso de humor, aspectos essenciais para ampliar a resistência e diminuir a vulnerabilidade. No convívio entre pessoas, criam-se vínculos que possibilitarão o surgimento de organizações ou, no mínimo, o seu incentivo, promovendo a inclusão social (GARCIA; YAGI; SOUZA, 2006).

A importância da experiência está no potencial de estimular a construção de conhecimentos por meio de uma perspectiva dialógica, interativa, em que os problemas e soluções são compartilhados, caracterizando-se como uma estratégia efetiva de promoção da saúde. E uma das estratégias que favorecem a ação integrada da equipe multiprofissional em processos de educação em saúde é a criação de grupos operativos com temáticas específicas relacionadas a patologia. Dessa forma, o objetivo do presente estudo é relatar a experiência do referido projeto, além de socializar a prática multiprofissional e interdisciplinar que se pactua.

\section{Metodologia de Ação}

O recrutamento de pacientes ocorre por meio de encaminhamentos ou demanda espontânea ao Serviço Integrado de Saúde da Universidade de Santa Cruz do Sul. A clientela que busca esta proposta de assistência integral é na maioria de idosos portadores de doenças não transmissíveis. A metodologia utilizada no projeto, busca trabalhar com dinâmicas grupais que favoreçam a expressão dos idosos sobre suas experiências de vida e conhecimentos sobre 
saúde, valorizando-se sua participação e o diálogo com o saber técnico-científico. O aprender fazendo e a criação de situações novas auxilia nos desafios postos do trabalho educativo.

Busca-se neste espaço trabalhar junto ao adulto maduro, exercitando o processo de ressignificar, rearticular, reelaborar e recriar o seu modo de ver-fazer as situações problema, na sua totalidade, num processo ação-reflexão-ação, interpretação-transformação, melhorando a qualidade de vida dos participantes e familiares, com isso, realizaram-se diversas dinâmicas pedagógicas, as quais consistem em atividades práticas, lúdicas e também palestras direcionadas aos participantes. Numa perspectiva reflexiva através do envolvimento e a participação efetiva dos coordenadores, professores-integrantes e bolsistas-alunos do projeto desde o planejamento (análise e levantamento de conhecimentos e necessidades, na elaboração dos objetivos), execução, até sua avaliação.

O acolhimento aos pacientes privilegia a escuta clínica e a intervenção de forma ampliada, seja nos atendimentos individuais, grupais, interconsultas ou qualquer momento de contato com o paciente no contexto dos atendimentos. Após cada intervenção, os dados colhidos são discutidos e analisados, sendo posteriormente anexados ao prontuário do paciente. Neste documentário se encontram todas as informações referentes ao mesmo, desde sua primeira consulta.

As atividades de acolhimento apresentam a duração de 30 a 45 minutos, abordando assuntos relacionados ao auto-cuidado da diabetes mellitus, hipertensão arterial, obesidade, hábitos alimentares saudáveis e auto-cuidado com saúde, dirigidas por bolsistas, acadêmicos voluntários e estagiários dos cursos de nutrição, psicologia e enfermagem, e em momentos especiais, tem-se a participação de acadêmicos do curso de educação física e outros palestrantes.

Para qualificar essa dinâmica, são realizadas reuniões sistemáticas, sessões de estudo, leituras complementares em busca de um constante aprofundamento teórico sobre as questões do envelhecimento, qualidade de vida e troca de experiências sobre o autocuidado, comportamento alimentar, autoestima e estilo de vida, todas com uma única proposta: educação em saúde preventiva.

Neste sentido os encontros educativos envolvem um conjunto de informações claras que englobam a alimentação, exercício físico, uso correto de fármacos, controle do stress, buscando motivar, entusiasmar e manter constante o interesse dos pacientes, para que participem ativamente no seu tratamento e assim, possa refletir em bons resultados para sua saúde. 
Em uma proposta de realização interativa (análise do realizado e elaborado), realiza-se a avaliação das atividades pelo próprio grupo e pelo público atingido. Sabe-se que uma das formas mais significativas de avaliação é aquela em que o próprio sujeito relata o que ele acredita que aprendeu e o que melhorou na sua saúde, a partir da sua participação no grupo.

\section{Refletindo sobre a prática}

O Projeto de Extensão Universitária Envelhecimento Saudável com enfase nas doenças crônico degenerativas caracteriza-se como uma atividade de extensão comunitária continuada. Entre março de 2008 a julho de 2009 mantem-se a mesma demanda, que permanece em torno de 98 participantes. Entre as atividades desenvolvidas, realizaram-se 82 interconsultas (estas realizadas conjuntamente com a equipe de enfermagem, psicologia e nutrição) com cada paciente, permitindo uma visão não fragmentada do processo saúde e doença, a partir de uma avaliação mais detalhada dos mesmos, sendo possível ter um diagnóstico e acompanhamento do estado nutricional, estado mental, níveis de glicemia e pressão arterial, consumo alimentar e estilo de vida.

Realizaram-se 69 práticas educativas, as quais apresentaram potencial para estimular o adulto maduro a refletir sobre a adoção de um estilo de vida saudável, bem como a construção de conhecimento, mediante as atividades de âmbito individual e coletivo.

Nos primeiros encontros foram pactuadas as atividades a serem trabalhadas no decorrer do semestre. Os temas foram são selecionados a partir da demanda dos participantes, sendo construídos e problematizados nos encontros de discussão da equipe multidisciplinar. Esse processo possibilitou uma integração positiva entre os participantes e a equipe, ao mesmo tempo em que proporcionou uma avaliação permanente das ações desenvolvidas.

Nos encontros seguintes, trabalhou-se com diferentes dispositivos, como figuras para falar de si, tendo como meta buscar uma aproximação maior entre acadêmicos e participantes. Constatou-se ser uma forma eficaz e descontraída para a expressão das subjetividades. Inicialmente surgiram mais aspectos positivos, mas também as angústias em relação, por exemplo, as privações alimentares. O objetivo buscado com esta técnica foi poder saber um pouco mais sobre as pessoas que ali estavam, conhecer mais da individualidade de cada um, podendo conhecer aspectos da vivência subjetiva. Esta dinâmica possibilita que o individuo possa olhar para si mesmo, podendo 
relatar através de uma forma lúdica sentimentos que ele muitas vezes evita entrar em contato. Conseguiu-se alcançar o objetivo com essa atividade, pois se percebeu que as pessoas escolheram figuras que realmente falavam delas e de seus sentimentos como saudade, raiva, tristeza, afeto, relações familiares, etc.

Neste momento observa-se que é preciso trazer mais do que palestras prontas, embora se reconheça a importância das mesmas para acrescentar informações aos participantes. Entendemos como um grande desafio, fazer com que os integrantes do grupo assumam um lugar ativo no seu processo de tratamento, onde estes possam exercer o papel que a eles é reservado, o de compartilhar vivências e trocar experiências e comprometimento com seu processo de qualidade de vida. Sempre tendo suas necessidades respeitadas e trabalhadas num processo cauteloso e gradativo, aos poucos se tem tentado estimular as trocas de experiências entre os integrantes do grupo. Foi identificado que muitos não utilizam esse espaço de encontros para trocarem experiências ou falar de suas vivências, eles realizam os exames clínicos (verificação dos níveis de $\mathrm{PA}^{5}$ e $\mathrm{HGT}^{6}$ ) e ficam aguardando a equipe acadêmica para dar início as palestras informativas, sobre temas de interesse grupal.

Após um semestre de atividades com o grupo, foram realizadas observações pelas bolsistas de psicologia, na sala de espera que antecede a realização de exames de verificação dos níveis de PA e HGT. Este é realizado pelos bolsistas e acadêmicos de enfermagem e o controle de peso e altura, realizado pelas bolsistas de nutrição, com o objetivo de ver que assuntos surgiriam durante esse tempo de espera pelos exames. Aproveitou-se este espaço para estimular os participantes a se escutarem e a trocar informações entre si, funcionando como um grupo de sala de espera. Infelizmente notouse que este grupo ainda encontra-se na pré-tarefa, quanto as relações de grupo, pois os participantes formam pequenos grupos de conversa, e não trocam informações entre o grande grupo, permanecendo a conversa em subgrupos (com dois ou três participantes). Diante desta observação, as acadêmicas da psicologia passaram a mudar o ambiente físico para estimular as trocas, modificando a disposição das cadeiras, com a intenção de provocar a aproximação entre os membros participantes, trazendo ao grupo a possibilidade de se escutar, compartilhar experiências e, tornarem-se mais ativos em seu processo terapêutico.

\footnotetext{
5 Pressão Arterial.

6 Hemoglucostet, mensuração nos níveis de colesterol e triglicerídios
} 
A distribuição das senhas por ordem de chegada também foi modificada, antes ficavam sobre uma mesa e as pessoas retiravam, independentemente de quem chegasse primeiro, o número da senha dificilmente se modificava. Optamos por uma nova experiência, a de entregar as senhas pessoalmente, seguindo à hora de chegada, com isso percebeu-se uma mudança no comportamento, pois as pessoas já haviam estabelecido certo lugar na fila. O que mostra que os participantes mantêm um lugar pré-estabelecido (definição de papéis), ou seja, mesmo não sendo o primeiro a chegar, certo participante era sempre o primeiro da fila (ZIMERMAN, 1997).

Aproveitando a ocasião da Páscoa, a primeira atividade do mês de abril foi uma oficina culinária de doces para diabéticos. Confeccionou-se um bolo de chocolate (cacau), biscoitos com farinha integral e suco de frutas, sobremesa de iogurte com mamão e docinhos de aveia com amendoim. Procuraram-se receitas que contassem com ingredientes saudáveis, demonstrando para o grupo a elaboração de receitas de doces, bolos e sobremesas utilizando adoçantes, ao mesmo tempo se aproveitou para falar um pouco sobre tipos de adoçantes, quais são adequados para forno e fogão, produtos dietéticos e controle da quantidade de adoçante consumido. Os próprios integrantes do grupo, prepararam as receitas com o auxílio das bolsistas da nutrição, enfermagem e psicologia, esse momento proporcionou uma reflexão rica entre a teoria e a prática. Todas as receitas foram preparadas com êxito e aprovadas pelo grupo.

A partir da prática na cozinha experimental iniciou-se uma série de dinâmicas visando orientar e estimular a alimentação saudável, a ação foi denominada Alimente-se bem, viva melhor!. Teve como objetivo sensibilizar e motivar os participantes do grupo a realizar mudanças efetivas no estilo de vida. Primeiramente, fez-se uma exposição sobre os benefícios de uma alimentação adequada e do controle de peso. Nesse momento o grupo pactuou o monitoramento do peso total do grupo, revelando uma preocupação com a manutenção de um peso adequado, pela relação direta que o mesmo possui com a hipertensão e diabetes melittos tipo 2.

Seguindo a proposta de trabalho, iniciaram-se paralelamente as avaliações individuais. Toda semana alguns pacientes eram entrevistados individualmente sobre sua rotina, atividade física, relação familiar, fumo, bebida, patologias, medicamentos utilizados, hábito intestinal e urinário, hábitos alimentares e algumas medidas antropométricas (peso, altura, índice de massa corporal e circunferência da cintura). A partir dos dados, construíram-se estratégias educacionais com o grupo e definiram-se metas coletivas e individuais em relação ao cuidado com a alimentação. Como muitos pacientes 
relataram ansiedade e compulsão alimentar, as acadêmicas da Psicologia passaram a acompanhar as avaliações, fornecendo também algumas orientações e fazendo encaminhamentos para atendimento psicológico quando necessário. Essa parceria mostrou-se de grande valor e possibilitou uma visão mais abrangente dos indivíduos e um melhor entendimento de cada pessoa.

Seguindo o desenvolvimento do tema Alimente-se bem, viva melhor!, intensificaram-se a orientação sobre boas escolhas alimentares, boas combinações de alimentos e tamanhos de porção. Esta atividade proporcionou uma roda de debate sobre as questões: você se alimenta bem? Por quê? Você acha que uma alimentação saudável é cara? Você acha que uma alimentação saudável é sem gosto? O preparo de uma refeição adequada é demorado? A primeira questão foi respondida individualmente por todos os indivíduos e as respostas foram debatidas pelo grupo, enquanto as demais foram lançadas para discussão. Como o grupo é bastante antigo, e a maioria dos membros já participa há bastante tempo, criou-se um vínculo de amizade e o hábito de estar ali todas as semanas.

Para avaliar a compreensão e recordar os assuntos discutidos nos encontros, foram distribuídas figuras de vários alimentos como abacate, leite, arroz, feijão, pão, frutas, frituras, refrigerante, entre outras. Cada participante falou o que sabia sobre o alimento que estava na figura recebida e todos ajudaram a complementar as explicações. Muito do que havia sido discutido anteriormente foi recordado pelos mesmos.

Ao longo do semestre, além das ações que visaram promover a integração no grupo na sala de espera que antecede os exames de rotina, continuaram sendo realizados os atendimentos individuais e interconsultas entre as áreas da nutrição e psicologia e, enfermagem e psicologia. Chegou-se a pensar em unir as três áreas na mesma consulta, mas isso poderia intimidar o paciente, pois seriam pelo menos três acadêmicas para entrevistá-lo e, além disso, se tornaria muito demorado, visto a quantidade de informações solicitadas pela enfermagem e nutrição.

Durante as interconsultas notamos que a grande maioria sabe o que está errando em relação à alimentação e admite que desconta na comida outros fatores, como ansiedade, relações familiares, de trabalho, etc. Inclusive muitos dos consultados assumem que embora saibam como melhorar a qualidade de vida em relação a saúde e alimentação, e a importância da prática de exercícios, não seguem esse padrão de vida. Alguns ainda complementam que, não conseguem se conter, ou justificam dizendo: "[...] agora está frio para caminhar, mas depois que esquentar um pouco eu vou começar." quando falam 
sobre a prática de exercícios. "Mas é tão gostoso, e eu como isso só de vez em quan$d o^{\prime \prime}$ referindo-se a determinados pratos.

Em algumas oportunidades, as acadêmicas de Psicologia se dividiam, uma permanência na sala de espera com os integrantes do grupo, e a outra circulava entre a sala de atendimento da equipe de Enfermagem e a sala de atendimento da Nutrição. Nestes momentos, foi possível observar que os participantes chegavam à sala de Enfermagem demonstrando preocupação e expectativa quanto ao resultado do exame de medição do nível da taxa de glicose, pois alguns relatavam ter se excedido na ingestão de doces durante o final de semana. Como nos casos observados os níveis estavam iguais ou até inferiores aos da semana anterior, na sala da Nutrição estes relatavam ter se controlado e diziam não ter consumido quase nada de doces durante a semana, observando-se a contradição nas falas.

Embora se esteja buscando um novo modelo de interação no grupo, estimulando a participação ativa dos integrantes, nota-se que o grupo espera pelas apresentações que abordem algum tema específico, pois dizem que através dessas palestras, aprendem e atualizam informações, e quando se opta pela realização de outras atividades que não envolvam palestras prontas eles cobram dos acadêmicos "e vocês não vão falar nada?".

Acredita-se que os participantes estão muito acostumados e acomodados a receber informações e, poucos compartilham seus conhecimentos e experiências, sendo que a maioria já participa do grupo há vários anos. Esse modelo que os torna agentes passivos no processo grupal, foi aplicado durante quase doze anos, diante dessa acomodação é que foi idealizada a criação um novo modo de interação, passando da passividade para a interação ativa e envolvimento de cada um no seu processo de promoção de qualidade de vida. A tentativa de implantação desse novo modelo grupal vem sendo feita aos poucos, através de uma integração da equipe que está sendo muito positiva, onde se cria espaços para conversas, planejamento e discussão das atividades e também de alguns casos atendidos através de interconsultas, o que enriquece muito nosso conhecimento enquanto equipe. Mas é um processo em construção, não só para os pacientes, mas também para a equipe, que precisa mudar a sua prática.

A finalidade no grupo e principalmente das interconsultas não é julgar se a pessoa segue ou não a recomendação, não se pune ninguém por não estar cuidando de si próprio, estamos apenas nos disponibilizando a esclarecer dúvidas, orientar sobre hábitos que podem ser evitados e outros que poderiam ser adotados por aqueles que sofrem com a diabetes e/ou hipertensão. Porém, não temos como controlar a vida desses sujeitos, o processo de 
saúde precisa ser assumido principalmente pela própria pessoa. Nosso papel é orientar e tentar conscientizar sobre a importância de cuidar de si, tanto na saúde física, psíquica e social, mas o processo de aderir ou não ao que lhes é orientado, cabe a cada um dos participantes.

Ao longo de 2009 contou-se com práticas de atividades físicas, desenvolvidas por uma estagiária do curso de Educação Física. A dinâmica envolveu atividades que sempre estiveram acompanhadas de música para dar ritmo e estimular os participantes a executá-las. No final das atividades realizava-se uma breve avaliação sobre o exercício executado, onde se buscava explicar a importância da prática de exercícios físicos, os cuidados que devem ser observados no momento da execução (alimentação e intensidade) e que benefícios estes poderiam estar trazendo para a saúde e qualidade de vida.

Rodrigues (2000) menciona que na educação para idosos, mais importante que o conteúdo propriamente dito é despertar a capacidade de confiança em si mesmo, sua autonomia e problematizar os estereótipos que poderão estar influindo negativamente em sua vida. Em consonância com o que propõe a autora, procurou-se, através de discussões coletivas, despertar uma participação mais ativa, valorizando as experiências pessoais e suas particularidades. Um outro tipo de metodologia utilizada foram as dinâmicas de grupo - atividades lúdicas adaptadas aos idosos - de caráter educativo, as quais oportunizaram ao grupo momentos de reflexão, alegria e descontração. Ainda sobre a metodologia desenvolvida, pode ser salientada que a realização de atividades práticas, como as oficinas culinárias relacionados à alimentação saudável e às plantas medicinais e os alongamentos realizados nas atividades físicas, caracterizaram-se como oportunidades para resgatar a consciência preventiva quanto às doenças e terapia medicamentosa.

Após as atividades pode-se perceber que os indivíduos que participaram das atividades grupais tiveram muita dificuldade de memorização e entendimento de temas teóricos, recomendando desenvolver estratégicas lúdicas e pedagógicas, na linha de educação popular, para melhor memorização dos temas estudados e adequação de seus limites e possibilidades de aprendizado para o autocuidado.

Apesar do trabalho ser grupal e não individual, a equipe deve estar aberta a conhecer e partilhar os constructos de cada um dos componentes do grupo, pois a situação humana vivenciada pelo paciente é única, quando o potencial humano pode e deve ser incentivado na busca do estar melhor. As histórias de vida dos participantes passam a fazer parte também das conversas do grupo. Existem momentos de descontração, que não estão planejados e que são extremamente ricos para o crescimento do grupo. 
Não temos a pretensão de afirmar que os trabalhos desenvolvidos pelo projeto estejam concluídos, mas, sim, dizer que muitas lacunas estão abertas e necessitam de continuidade no que está por vir. Muito necessita ser feito para que estas lacunas sejam preenchidas, cabe a equipe de professores e bolsistas abordar as transformações contínuas que ocorrem no mundo, não permitindo a estagnação de ações, mas sim a progressão destas, sempre através da atuação interdisciplinar.

As dinâmicas do grupo estimularam a relação interpessoal entre os indivíduos e os profissionais de saúde, facilitaram a discussão entre pessoas com os mesmos objetivos, possibilitando a troca de informações. Apesar das limitações metodológicas, é possível concluir que o processo educativo alcançou bons resultados, foi possível observar a boa aceitação nas ações preventivas e cuidativas dos indivíduos em relação as suas patologias e, no monitoramento nos níveis da glicemia e pressão arterial, prevenindo complicações futuras.

Essa abordagem mais abrangente das atividades em grupo proporcionou pontes de interseção entre o saber acadêmico e o saber popular. Assim como, o compartilhar e dialogar com outras pessoas, que estão vivenciando o processo de saúde-doença semelhante aos seus, proporcionam momentos de relação e trocas de experiências extremamente fecundas, podendo proporcionar uma reestruturação pessoal de suas próprias vivências através destas relações intersubjetivas.

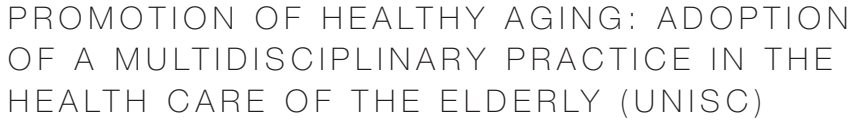

PROMOTION OF HEALTHY AGING: ADOPTION OF A MULTIDISCIPLINARY PRACTICE IN THE HEALTH CARE OF THE ELDERLY (UNISC)

\section{abstract}

This article aims to share the experience of a project of the University Extension of Santa Cruz do Sul (UNISC), Promotion of Healthy Aging - Adoption of a multidisciplinary practice in the Health Care of the Elderly, which includes nursing, nutrition and psychology. It is developed since 1997 and has been adjusting to the realities, with reference to the experience of teachers in the actions for the aging, quality of life, held for ten years by an interdisciplinary team of Integrated Health Services, medical-school UNISC. The goal is to 
socialize the experience, which brings together seniors throughout the year to discuss issues related to health in aging. Each area, through its expertise, through meetings of seeking health care and individualized collectively build a better process of care. Interlocutions moments occur with the rich exchange of experiences, knowledge, information and assistance so that the user is perceived in its entirety and look forward the responsibility to your health. The results show an improvement in the level of health, reducing complications arising from chronic diseases.

keywords

Aging. Multiprofessional. Operative Groups.

\author{
referências
}

ASSIS, Mônica de. Promoção da saúde e envelhecimento: avaliação de uma experiência no ambulatório do Núcleo de Atenção ao Idoso da UnATI/UERJ. 2004. 220f. Tese (Doutorado em Saúde Pública) - Escola Nacional de Saúde Pública-ENSP/FIOCRUZ, Rio de Janeiro, 2004.

GARCIA, Maria Alice Amorim et al. Atenção à saúde em grupos sob a perspectiva dos idosos. Revista Latino-Americana de Enfermagem, Ribeirão Preto, mar./abr. 2006, v. 14, ก. 2, p. 175-182.

RODRIGUES, Nara Costa. Envelhecimento e Cidadania. In: SCHONS, C. R.; PALMA, L. T. S. (Org.). Conversando com Nara Costa Rodrigues sobre Gerontologia Social. Passo Fundo: UPF Editora, p. 77-81, 2000.

VASCONCELLOS, Eymard Mourão. Educação Popular e a Atenção à Saúde da Familia. São Paulo: Editora Hucitec, 1999.

ZIMERMAN, David Epelbaum (Org.). Como trabahamos com grupos. Porto Alegre: Editora Artes Médicas, 1997.

Recebido: 24/08/2009

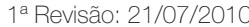

2a Revisão: 30/09/2010

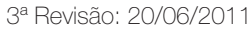

Aceite Final: 21/06/2011 